\title{
A Clinical Study on Gestational Diabetes Mellitus and the Hearing of Newborns
}

\author{
Jun-Hong Zhou ${ }^{1, *}$ \\ Kang $\mathrm{Yu}^{2, *}$ \\ Hui Ding' \\ Zhao-Hua Zhu ${ }^{3, *}$ \\ Li-Hua Han ${ }^{1} *$ \\ Ting Zhang (1D' \\ 'Department of Obstetrics, Sunshine \\ Union Hospital, Weifang, 261000, \\ Shandong, People's Republic of China; \\ ${ }^{2}$ The Reproductive Medicine Center of \\ Weifang People's Hospital, Weifang, \\ 261000, Shandong, People's Republic of \\ China; ${ }^{3}$ Department of Obstetrics, \\ Traditional Chinese Medicine Hospital of \\ Weifang, Weifang, 261000, Shandong, \\ People's Republic of China \\ *These authors contributed equally to \\ this work
}

\begin{abstract}
Objective: This study aimed to explore the impact of gestational diabetes mellitus (GDM) on the results of newborn hearing screening.

Methods: A total of 666 pregnant women who gave birth in the Obstetric Department of Sunshine Ronghe Hospital from August 2017 to May 2018 were randomly selected, and 69 of these pregnant women had GDM and were assigned into group 1 (excluding other diseases). The average age of these patients was 31.07 years. A further 597 pregnant women had no GDM and were assigned into group 2 (excluding other diseases). The average age of these patients was 30.02 years. The results of newborn hearing screening results in group 1 and group 2 were compared.

Results: Comparisons of abnormal hearing screening between 2 groups are significant different $(\mathrm{P}<0.05)$. In the GDM group, the results of hearing screening of newborns delivered by vaginal delivery and cesarean delivery were compared, yielding a P-value of $>0.05$, and the difference was not statistically significant. In the non-GDM group, the results of hearing screening of newborns delivered by vaginal delivery and cesarean delivery were compared, yielding a P-value of $>0.05$, and the difference was not statistically significant. Conclusion: GDM increases the incidence of abnormal hearing in newborns.

Keywords: diabetes, pregnancy, newborn, hearing screening, otoacoustic emission
\end{abstract}

\section{Introduction}

At present, the incidence of diabetes in pregnancy (DIP) and gestational diabetes mellitus (GDM) increases year by year. ${ }^{1-3}$ GDM has become one of the most common comorbidities during pregnancy in China. Mothers with GDM and their infants have been identified as high-risk populations for diabetes mellitus. ${ }^{4}$ Neonatal hearing impairment is a common congenital disability and one of the screened diseases with the highest incidence in newborns. ${ }^{5,6}$ The incidence is $0.1-0.3 \%{ }^{7}$ The overall goal of neonatal hearing screening is to detect children with hearing impairment early, and to treat them timely, to reduce the impact on language development and other neurological and mental development, and improve the wellbeing of the population. ${ }^{8}$ More than $80 \%$ of pregnant patients with diabetes mellitus have GDM, and less than $20 \%$ of them have pregestational diabetes mellitus. ${ }^{9,10}$ It is reported that the incidence of GDM is $1-14 \%$ in the world, and the incidence is $1-5 \%$ in China. In recent years, the incidence is increasing. ${ }^{11}$ It is of great significance for mothers and infants with GDM to explore the impact of GDM on hearing screening results in newborns, strengthen the management of pregnant women with GDM, and prevent the occurrence of neonatal hearing impairment.
Correspondence: Ting Zhang; Hui Ding Department of Obstetrics, Sunshine Union Hospital, No. 9000 of Yingqian Street, Kuiwen District, Weifang, 261000 Shangdong, People's Republic of China Tel +86 I5I69502878

Email zhangting_nn@163.com; dinghui88con@163.com 


\section{Subjects and Methods}

\section{Subjects}

Discharge records of patients with gestational diabetes mellitus and patients without gestational diabetes mellitus were randomly selected from one floor between August 2017 and May 2018. Patients in both groups had no other medical complications. Power is 0.8 . A total of 666 pregnant women who gave birth in the Obstetric Department of Sunshine Ronghe Hospital from August 2017 to May 2018 were randomly selected. Of these, 69 women had GDM and were assigned into group 1, while 597 of these women had no GDM and were assigned into group 2 . The exclusion criteria of the two groups were as follows: pregnant women with pregnancy comorbidities and complications. In this study, a retrospective analysis was performed, and the relationship between GDM and neonatal hearing screening abnormality was evaluated by comparing groups 1 and 2 .

The study was conducted in accordance with the Declaration of Helsinki (as was revised in 2013). The study was approved by Ethics Committee of Sunshine Union Hospital and informed consent was taken from all the patients.

\section{Diagnostic Criteria of GDM}

The diagnosis was made according to the health industry standard WS 331-2011 of the People's Republic of China, that is, the diagnostic criteria of GDM. The 75 -g oral glucose tolerance test (OGTT) was performed. The diagnostic values of fasting blood glucose and blood glucose one and two hours after taking glucose were 5.1, 10.0, and $8.5 \mathrm{mmol} / \mathrm{L}$, respectively. When any of the three items meet or exceed the above criteria, the patient is diagnosed with GDM. ${ }^{9}$

\section{Neonatal Hearing Screening Methods}

Using the TYPE 1077 automatic otoacoustic emission (OAE) instrument produced by Natus (Denmark), the infants were tested in a sleep quiet state after feeding. The steps of otoacoustic emission were as follows: the ear canal was firstly cleaned with a cotton swab to remove ear wax and other secretions, then a probe was gently inserted to test both ears separately. The results were processed by computer, then shown the results: passed, failed. If the result showed a fail, the test was repeated 2-3 times. Otoacoustic emission is rigorous technical work. The diagnosis and treatment require excellent technology by the professionals, and the screening level is high. For those who failed the preliminary screening, a hearing recheck notice was issued to the parents. Those who failed the recheck within 42 days were referred to Weifang Maternal and Child Health Hospital for diagnostic hearing examination.

\section{Statistical Analysis}

Data were statistically analyzed using statistical software SPSS 23.0. A Chi-square test was used to compare the data. $\mathrm{P}<0.05$ was considered statistically significant.

\section{Results}

All patients were 20-44 years old, with an average age of (30.0 \pm 4.6$)$ years old. Pregnancy weight gain of $5-30 \mathrm{~kg}$, the average increase (13.9 \pm 4.9$)$; At admission, the BMIwas $20.4-44.5 \mathrm{Kg} / \mathrm{m} 2$, and the mean BMI was $29.9 \pm 8.9$. The average gestational age was (39.1 \pm 2.8$)$ from 37 to 42 weeks.

Comparisons of abnormal hearing screening between 2 groups are significant different $(\mathrm{P}<0.05)$ (Table 1). In the group with GDM, the results of the hearing screening of newborns delivered by vaginal delivery and cesarean delivery were compared, yielding a P-value of $>0.05$. The difference was not statistically significant (Table 2). In the group without GDM, the results of the hearing screening of newborns delivered by vaginal delivery and cesarean delivery were compared, yielding a P-value of $>0.05$. The difference was not statistically significant (Table 3).

\section{Discussion}

GDM can cause high risk in pregnancy. A study revealed that as a woman's blood glucose level increases during pregnancy, the risks, such as premature delivery, cesarean section, shoulder dystocia or labor injury, preeclampsia, delivery of larger than gestational-age infants, increased umbilical cord blood C-peptide level, neonatal hypoglycemia, neonatal hyperbilirubinemia, and neonatal admission

Table I Comparison of Hearing Screening Results of Newborns Between Pregnant Women with Different Delivery Modes

\begin{tabular}{|l|c|c|c|c|}
\hline Groups & Cases & $\begin{array}{c}\text { Abnormal } \\
\text { Hearing } \\
\text { Screening: Failed } \\
\text { (\%) }\end{array}$ & $\begin{array}{c}\text { Normal } \\
\text { Hearing } \\
\text { Screening } \\
\text { (\%) }\end{array}$ & \\
\hline Group I & 69 & $3(4.35)$ & $66(95.65)$ & \multirow{2}{*}{$P<0.05$} \\
\hline Group 2 & 597 & $7(1.17)$ & $590(98.83)$ & \\
\cline { 1 - 4 } Total & 666 & $10(1.50)$ & $656(98.50)$ & \\
\hline
\end{tabular}


Table 2 Comparison of the Results of Hearing Screening of Newborns Delivered by Vaginal Delivery and Cesarean Delivery in the GDM Group

\begin{tabular}{|l|c|c|c|}
\hline Groups & Cases & $\begin{array}{c}\text { Abnormal Hearing Screening: Failed } \\
\text { (\%) }\end{array}$ & $\begin{array}{c}\text { Normal Hearing Screening } \\
\text { (\%) }\end{array}$ \\
\hline Delivered by vaginal delivery & 31 & $\mathrm{I}(3.23)$ & $30(96.77)$ \\
\hline Delivered by cesarean delivery & 38 & $2(5.26)$ & $36(94.74)$ \\
\hline Total & 69 & $3(4.35)$ & $66(95.65)$ \\
\hline
\end{tabular}

Table 3 Comparison of the Results of Hearing Screening of Newborns Delivered by Vaginal Delivery and Cesarean Delivery in the Non-GDM Group

\begin{tabular}{|l|c|c|c|c|}
\hline Groups & Cases & Abnormal Hearing Screening: Failed (\%) & Normal Hearing Screening (\%) & $424(99.30)$ \\
\hline Vaginal delivery & 427 & $3(0.70)$ & $166(97.65)$ \\
\hline Cesarean delivery & 170 & $4(2.35)$ & 590.05 \\
\hline Total & 597 & $7(1.17)$ & $58.83)$ \\
\hline
\end{tabular}

to ICU, also increase. ${ }^{12}$ The correlation is continuous. Even a slight increase in blood glucose levels during pregnancy can have adverse effects on pregnancy outcomes. ${ }^{13}$ Should obstetricians regulate the management of GDM patients? Early diagnosis, early treatment, and blood glucose control should be given as far as possible to reduce the incidence of maternal and neonatal complications in patients with GDM. ${ }^{14}$ This study aimed to identify other complications of GDM, to further strengthen the management of GDM, paying attention to GDM, and to actively control blood glucose to reduce its adverse effects on mother and infant.

In 2000, after recognizing the importance and necessity of universal newborn hearing screening, the Chinese government included neonatal hearing screening into the routine examination items of child health care and began to carry this out across the whole country. The current hearing screening program in China consists of two steps: primary screening and re-screening. Healthy newborns complete OAE or AABR preliminary hearing screening before discharge. Newborns in the neonatal intensive care unit (NICU) complete OAE and AABR screening after their condition stabilizes. Those who fail the hearing screening are given a hearing re-screening at 42 days. Those who fail the re-screening receive a comprehensive audiological diagnosis within three months. Audiological intervention is given within six months of age, after hearing loss is determined. ${ }^{15}$ The neonatal screening methods in our hospital meet the national requirements. If a newborn cannot hear sounds clearly after birth, the lack of stimulation of language and environmental sounds in the critical period of language (less than three years old) will affect language development in the future, leading to unclear sound discrimination in mild cases, and causing hearing and speech disorders in severe cases. Hearing impairment is a common congenital disability. Hearing loss in infants and young children directly affects the formation of language. The main manifestations are unclear pronunciation. In severe cases, it can even lead to the child becoming deaf and mute. ${ }^{16}$ Furthermore, a lack of language development may also affect the development of the child's psychology, intelligence, and social communication ability, which can lead to a heavy burden on society and the child's family. ${ }^{17,18}$ If newborns with this disorder are screened and diagnosed shortly after birth, we can promote the development of hearing and language of these children through intervention and treatment. This may mean that they are deaf but not mute. Therefore, it is necessary to conduct hearing screening for newborns. It is of great significance to study the influencing factors of neonatal hearing screening abnormalities.

\section{Conclusion}

In summary, this study revealed that GDM has an impact on the hearing of newborns. For high-risk populations, timely intervention, standardized treatment, a reasonable diet, and appropriate physical activity should be implemented, and blood glucose should be controlled. The 
relevant screening and follow-up work should be strengthened, and early intervention programs should be studied and developed.

\section{Acknowledgments}

We are particularly grateful to all the people who have given us help on our article.

\section{Funding}

There is no funding to report.

\section{Disclosure}

The authors declare that they have no competing interests.

\section{References}

1. Egan AM, Vellinga A, Harreiter J, et al. Epidemiology of gestational diabetes mellitus according to IADPSG/WHO 2013 criteria among obese pregnant women in Europe. Diabetologia. 2017;60 (10):1913-1921. doi:10.1007/s00125-017-4353-9

2. Zhu Y, Zhang C. Prevalence of gestational diabetes and risk of progression to type 2 diabetes: a global perspective. Curr Diab Rep. 2016;16(1):7. doi:10.1007/s11892-015-0699-x

3. Lee KW, Ching SM, Ramachandran V, et al. Prevalence and risk factors of gestational diabetes mellitus in Asia: a systematic review and meta-analysis. BMC Pregnancy Childbirth. 2018;18(1):494. doi:10.1186/s12884-018-2131-4

4. Gao C, Sun X, Lu L, Liu F, Yuan J. Prevalence of gestational diabetes mellitus in mainland China: a systematic review and meta-analysis. $J$ Diabetes Investig. 2019;10(1):154-162. doi:10.1111/jdi.12854

5. Escobar-Ipuz FA, Soria-Bretones C, García-Jiménez MA, Cueto EM, Torres Aranda AM, Sotos JM. Early detection of neonatal hearing loss by otoacoustic emissions and auditory brainstem response over 10 years of experience. Int $J$ Pediatr Otorhinolaryngol. 2019;127:109647. doi:10.1016/j.ijporl.2019.109647
6. Vashistha I, Aseri Y, Singh BK, Verma PC. Prevalence of hearing impairment in high risk infants. Indian $J$ Otolaryngol Head Neck Surg. 2016;68(2):214-217. doi:10.1007/s12070-015-0869-9

7. Wang XJ, Li YM, Zhang HF, et al. Advances in neonatal hearing screening and risk factors for hearing loss. Maternal Child Health Care China. 2013;28(16):2641-2644.

8. Patel H, Feldman M. Universal newborn hearing screening. Paediatr Child Health. 2011;16(5):301-310. doi:10.1093/pch/16.5.301

9. American Diabetes Association. Standards of medical care in diabetes--2010. Diabetes Care. 2010;33(Suppl 1):S11-S61. doi:10.2337/dc10-S011.

10. Plows JF, Stanley JL, Baker PN, Reynolds CM, Vickers MH. The pathophysiology of gestational diabetes mellitus. Int $J$ Mol Sci. 2018;19(11):3342. doi:10.3390/ijms 19113342

11. Hou MD. An analysis of the impact of gestational diabetes on mother and child. Womens Health Res. 2011;31(8):172-174.

12. Sudasinghe BH, Wijeyaratne CN, Ginige PS. Long and short-term outcomes of Gestational Diabetes Mellitus (GDM) among South Asian women - a community-based study. Diabetes Res Clin Pract. 2018;145:93-101. doi:10.1016/j.diabres.2018.04.013

13. HAPO Study Cooperative Research Group; Metzger BE, Lowe LP, et al. Hyperglycemia and adverse pregnancy outcomes. $N$ Engl J Med. 2008;358(19):1991-2002. doi:10.1056/NEJMoa0707943.

14. Liu B, Xu Y, Zhang Y, et al. Early Diagnosis of Gestational Diabetes Mellitus (EDoGDM) study: a protocol for a prospective, longitudinal cohort study. BMJ Open. 2016;6(11):e012315. doi:10.1136/bmjopen2016-012315

15. Wu WJ, Tang XR, Li Y, et al. Neonatal hearing screening in remote areas of China: a comparison between rural and urban populations. J Int Med Res. 2018;46(2):637-651. doi:10.1177/0300060517706643

16. Korver AM, Smith RJ, Van Camp G, et al. Congenital hearing loss. Nat Rev Dis Primers. 2017;3:16094. doi:10.1038/nrdp.2016.94

17. Burke MJ, Shenton RC, Taylor MJ. The economics of screening infants at risk of hearing impairment: an international analysis. Int J Pediatr Otorhinolaryngol. 2012;76(2):212-218. doi:10.1016/j. ijporl.2011.11.004

18. Du XH, Luo HQ, Chang J. The significance of glycemic control in improving pregnancy outcomes in pregnant women with gestational diabetes mellitus. J Pract Obstet Gynecol. 2008;24(8):501-503.

\section{Publish your work in this journal}

Diabetes, Metabolic Syndrome and Obesity: Targets and Therapy is an international, peer-reviewed open-access journal committed to the rapid publication of the latest laboratory and clinical findings in the fields of diabetes, metabolic syndrome and obesity research. Original research, review, case reports, hypothesis formation, expert opinion and commentaries are all considered for publication. The manuscript management system is completely online and includes a very quick and fair peer-review system, which is all easy to use. Visit http://www.dovepress.com/testimonials.php to read real quotes from published authors. 